\title{
ANÁLISE DOS DESAFIOS E LIMITAÇÕES PARA O TURISMO EM CAPÃO DA CANOA NO LITORAL NORTE DO RIO GRANDE DO SUL
}

\author{
ANALYSIS OF CHALLENGES AND LIMITATIONS FOR \\ TOURISM IN CAPÃO DA CANOA - RIO GRANDE DO SUL
}

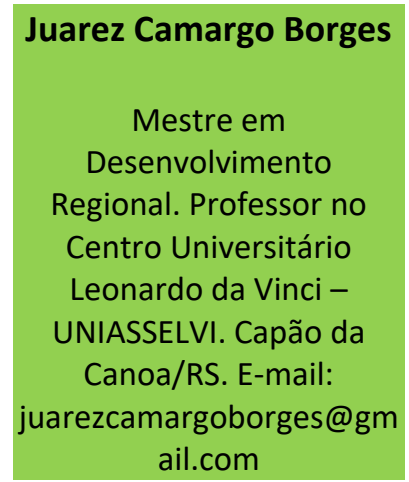

\section{RESUMO}

Neste estudo, visa-se apresentar as potencialidades para o desenvolvimento do turismo em Capão da Canoa na região do litoral norte do Rio Grande do Sul. Além disso, buscam-se identificar os desafios e as limitações para o desenvolvimento e a gestão do território urbano na exploração do potencial turístico. Assim, essa proposta de natureza qualitativa, exploratória e descritiva vai além da revisão teórica, uma vez que o autor pretende apresentar também as potencialidades de desenvolvimento do turismo a partir da análise documental do Planejamento Estratégico do Conselho Regional de Desenvolvimento do Litoral. Nesta análise, é possível verificar que o turismo pode contribuir para o desenvolvimento regional, mas é necessário analisar uma série de fatores que potencializam e limitam essa atividade. O litoral poderá conquistar em longo prazo benefícios sociais, econômicos e ambientais que dependem dos instrumentos de planejamento territorial.

Palavras-chave: Turismo. Desafios e limitações. Litoral norte.

\begin{abstract}
In this study, the aim is to present the potential for the development of tourism in Capão da Canoa, located on the North Coast of Rio Grande do Sul. In addition, we seek to identify the challenges and limitations to the development and management of the urban territory in the exploration of the touristic potential. Thus, this proposal of a qualitative, exploratory and descriptive nature goes beyond the theoretical review, since the author intends to also present the potentialities of tourism development based on the documentary analysis of Strategic Planning of the Regional Council for Coastal Development. In this analysis it is possible to verify that tourism can contribute to the regional development, but it is necessary to analyze a series of factors that potentiate and limit this activity. The coastline can achieve in a long therm social, economical and environmental benefits, that depend on the instruments of territorial planning.
\end{abstract}

Keywords: Tourism. Challenges and limitations. North Coast. 


\section{INTRODUÇÃO}

O segmento do turismo tem apresentado, nas últimas décadas, um crescimento relevante comparado a outros serviços. O desenvolvimento tecnológico e a melhoria das condições econômicas das pessoas, “[...] aliados à necessidade de evasão, de fuga dos grandes centros urbanos, alteraram o setor do turismo" (ANSARAH, 2001, p. 17).

O litoral norte do Rio Grande do Sul tem apresentado uma dinâmica demográfica diferenciada em relação ao restante do estado. É possível citar o turismo como componente do desenvolvimento da região do litoral norte, pois essa atividade desencadeia a vinda de inúmeras empresas à cidade como restaurantes, hotéis e o comércio em geral. Isso acontece, principalmente, no setor do mercado imobiliário e da construção civil. Assim, consequentemente, muitos postos de trabalho são gerados a partir dessa dinâmica do processo de desenvolvimento do litoral norte do Rio Grande do Sul.

Os autores Fernandes e Pereira (2017, p. 544) destacam que o desenvolvimento do turismo de um município depende de um plano de ação do governo municipal, “[...] dividido em programas voltados para frentes de trabalho do turismo no município, por exemplo, ensino de turismo, segurança, saneamento, abastecimento, comunicação, saúde, dentre outros”. Dessa forma, destaca-se a importância de estudos na tentativa de compreender o fenômeno do turismo na região do litoral norte do Rio Grande do Sul e a importância dos instrumentos de planejamento e gestão do território.

O fenômeno do turismo em Capão da Canoa, assim como em todos os municípios praianos do litoral, contribui para o processo de urbanização. Isso impacta também nas demandas de outros produtos e serviços dessa atividade, por exemplo, serviços públicos como educação, saúde e tratamento de água e esgoto, mobilidade urbana e habitação para a população mais vulnerável, levando o município a acumular problemas com demandas sociais.

Dessa forma, neste estudo, de natureza qualitativa, exploratória e descritiva, que vai além da revisão teórica, apresentar-se-ão as potencialidades de desenvolvimento do turismo em Capão da Canoa na região do litoral norte do Rio Grande do Sul. O estudo identificará os desafios e as limitações para o desenvolvimento e a gestão do território urbano na exploração do potencial turístico.

Assim, discutir-se-á, na sequência, o embasamento teórico realizado por meio de uma pesquisa bibliográfica acerca do tema central “[...] turismo e desenvolvimento regional". $\mathrm{O}$ autor visa enfatizar, de maneira descritiva e qualitativa, as principais e mais relevantes características do lugar com análises e reflexões sobre os fatores que potencializam e limitam 
o desenvolvimento do turismo. E, por fim, mostrar-se-ão as considerações finais que complementam as análises.

\section{O TURISMO COMO ATIVIDADE DE DESENVOLVIMENTO REGIONAL}

O turismo, na economia nacional, segundo Barretto (1995, p. 72), “[...] tem efeitos econômicos diretos e indiretos na economia de um país". O autor destaca o efeito dos gastos do turista no território, uma vez que o dinheiro é trazido de fora pelo turista para pagar os produtos e serviços consumidos.

“O efeito multiplicador é produzido pela sucessão de despesas que tem origem no gasto do turista e que beneficia os setores ligados diretamente e os ligados indiretamente ao fenômeno turístico" (BARRETTO, 1995, p. 74). Quanto ao dinheiro trazido pelo turista, o autor relaciona os incrementos que são multiplicados na economia, por exemplo:

a) aumento da urbanização;

b) incremento das indústrias associadas;

c) incremento da mão de obra para serviços turísticos;

d) incremento da indústria da construção e da demanda de mão de obra respectiva;

e) aumento da demanda de produtos locais desde hortifrutigranjeiros e artesanato;

f) maior arrecadação de impostos e de taxas.

De acordo com Sancho (2001, p. 3), "O turismo compreende as atividades que realizam as pessoas durante suas viagens e estadas em lugares diferentes ao seu entorno habitual, por um período consecutivo inferior a um ano, com finalidade de lazer, negócio ou outros". A atividade do turismo demanda de uma série de outros produtos e serviços de uma determinada região, formando uma cadeia de consumo, o que potencializa desenvolvimento regional.

\footnotetext{
É nesse contexto que o turismo se revela um importante aliado para impulsionar o desenvolvimento econômico, pois, nas últimas décadas, o setor apresentou crescimento contínuo e se destacou como um dos mais significativos da economia global, pela sua capacidade de geração de emprego, renda e atração de investimentos. Segundo a Organização Mundial de Turismo (OMT), atualmente o volume de negócios do setor é igual ou superior ao das exportações de petróleo, de produtos alimentícios ou de automóveis, tornando o segmento um dos principais atores do comércio internacional. (MINISTÉRIO DO TURISMO, 2018, p. 23).
}

Para Sen (2000, p. 28), “[...] uma concepção adequada de desenvolvimento deve ir além da acumulação de riqueza e do crescimento do Produto Nacional Bruto e de outras variáveis relacionadas à renda”. Quanto à potencialidade do turismo contribuir para o desenvolvimento de uma região, é importante destacar que o desenvolvimento abrange o 
plano econômico e o plano social. Porém, quando se percebe o aumento dos índices de roubo, casos de prostituição e degradação ao meio ambiente, verificada principalmente pela contaminação das águas, têm-se então que, "em lugar de benefícios sociais, em alguns lugares o turismo trouxe degradação" (BARRETO, 1995, p. 92). Dada sua importância e inegável contribuição para o desenvolvimento, o turismo precisa ser estudado além do aspecto econômico.

\begin{abstract}
Desenvolvimento, em termos conceituais, pode ser descrito observando-se duas linhas de pensamento econômico. Uma, de natureza teórica, considera desenvolvimento como sinônimo de crescimento econômico, e, outra, voltada mais para a realidade empírica, considera imprescindível adicionar ao crescimento de indicadores que possam refletir melhorias nas condições de vida das pessoas, tais como: saúde, educação, segurança e qualidade ambiental (ARAÚJO et al. 2017, p. $6)$.
\end{abstract}

Conforme Moser e Muller (2002, p. 63), "O turismo deve ser objeto de intenso planejamento, apoiando propostas que representem ganhos reais para a comunidade e minimizem os seus aspectos negativos". O planejamento do turismo e o envolvimento de diversas áreas do conhecimento no estudo desse complexo fenômeno envolvem a diversidade de técnicas e o entendimento da singularidade dos espaços ditos turísticos (FERNANDES; PEREIRA, 2017).

É importante identificar o turismo como setor produtivo e torná-lo competitivo, considerando que o elemento-chave do desenvolvimento regional é a capacidade de atender as diversas demandas oriundas do turismo (TOMAZZONI, 2009). A falta de planejamento no turismo e os impactos negativos têm gerado questionamentos sobre as potencialidades reais de desenvolvimento regional por meio do turismo.

Segundo o Ministério do Turismo, "O turismo será cada vez mais importante no contexto da economia nacional" (MINISTÉRIO DO TURISMO, 2018, p.16). E ele pode apresentar algumas vantagens em aspectos econômicos, principalmente na geração de empregos. Segundo Moser e Muller (2002, p. 63):

[...] destaca-se a própria facilidade de através de promoções e novos investimentos, geram mais e mais empregos, sem esquecer que tem a peculiaridade de gerar vagas em áreas com desemprego estrutural, como centros de cidades e áreas rurais, e promover a melhoria da qualidade de vida dos membros da comunidade.

É importante desenvolver estudos sobre o turismo no sentido de alcançar metas de desenvolvimento sem esgotar os recursos naturais. Ansarah (2001) destaca o turismo sustentável como um modelo viável de desenvolvimento econômico capaz de melhorar a 
qualidade de vida da comunidade receptora, proporcionar ao turista uma experiência de qualidade e manter a qualidade do meio ambiente de que tanto a comunidade anfitriã como os visitantes dependem.

\begin{abstract}
O turismo no espaço rural surge como um negócio que possibilita aos proprietários manter suas propriedades produtivas, além de gerar empregos à população local. Também desperta a consciência e a compreensão ecológica, transformando-a em agente conservadora da natureza, sobretudo quando percebe a atividade turística como fonte de economia. (ANSARAH, 2001, p. 146).
\end{abstract}

A riqueza ambiental e a diversidade do patrimônio são fatores que constituem um grande potencial para conquistar o mercado e tornar o turismo um dos principais setores de ingresso de divisas para a economia nacional (TOMAZZONI, 2009). No litoral norte do Rio Grande do Sul, recorte territorial deste estudo, é possível verificar o potencial de desenvolvimento de atividades de turismo de veraneio e rural por se tratar de uma região rica em atrativos naturais. Porém, não existe um roteiro turístico integrado que contemple esses atrativos, potencializando o turismo de praia, o rural e o ecológico.

\title{
3 O POTENCIAL DE DESENVOLVIMENTO NO LITORAL NORTE
}

Neste item, serão apresentados alguns aspectos que determinam o turismo como vocação para o crescimento econômico do litoral norte, bem como os aspectos potencializadores e limitadores do desenvolvimento.

Com base no diagnóstico realizado pelo Conselho Regional de Desenvolvimento (COREDE), o litoral é composto por vinte e um municípios, que são: Arroio do Sal, Balneário Pinhal, Capão da Canoa, Capivari do Sul, Caraá, Cidreira, Dom Pedro de Alcântara, Imbé, Itati, Mampituba, Maquiné, Morrinhos do Sul, Mostardas, Osório, Palmares do Sul, Terra de Areia, Torres, Tramandaí, Três Cachoeiras, Três Forquilhas e Xangri-Lá (COREDE, 2017). Desses 21 municípios, o COREDE destaca como sendo os municípios mais populosos Capão da Canoa, Tramandaí, Osório e Torres, com populações em torno de 40 mil habitantes. Os demais municípios são menores.

O Litoral é um polo de grande atração de população, não só no veraneio - que nos meses de dezembro a março quadruplica a população - mas também há nas últimas décadas um grande fluxo de migração para o Litoral, com esta região tendo as maiores taxas de crescimento populacional do Estado. Tal fluxo migratório incidiu sobre a necessidade de uma grande urbanização na região, muitas vezes sem o devido planejamento, trazendo problemas comuns a toda grande cidade, como precariedade do transporte público, falta de rede e tratamento de esgoto, má gestão dos resíduos sólidos, entre outros temas mais específicos, como o conflito na utilização das faixas de lagoas e praias (COREDE, 2017, p. 75). 
É importante ressaltar que, de acordo com Ansarah (2001, p. 22), “As exóticas construções [...] destoam da paisagem, os grandes edifícios em cidades praianas". O litoral apresenta uma cultura de valorização de espaços privilegiados por uma paisagem natural, principalmente para o mercado imobiliário na construção de loteamentos horizontais fechados e condomínios residenciais de luxo nestes espaços de beleza cênica (STROHAECKER, 2007).

Para manter esse patamar de crescimento e promover o turismo de forma efetiva e com qualidade, é absolutamente necessária a constante realização de pesquisas que nos permita conhecer, além do número de turistas, suas necessidades, bem como detectar a demanda potencial (ANSARAH, 2001, p. 9).

Estudos destacam que, devido ao surgimento de novas demandas, a região tornou-se foco para novos empreendimentos, especialmente no setor de serviços de pequeno e médio porte não especializado. Nos últimos 20 anos, grandes empresas de caráter internacional e também regional se estabeleceram no local, formando um polo de centralidade em Capão da Canoa, Osório, Torres e Tramandaí. Nesses municípios, a população é predominantemente urbana e a principal atividade econômica é o turismo sazonal, de veraneio. No litoral, também se destaca o forte investimento em implantação de parques eólicos (STROHAECKER, 2007).

Quadro 1 - potencialidades de desenvolvimento dos municípios

\begin{tabular}{|c|c|c|}
\hline Categorias de Municípios & Relação dos Municípios & Potencialidades e tendências \\
\hline $\begin{array}{l}\text { Urbanos Permanentes e } \\
\text { Urbanos para fins de segunda } \\
\text { residência. }\end{array}$ & $\begin{array}{l}\text { Capão da Canoa; } \\
\text { Osório; } \\
\text { Tramandaí; e } \\
\text { Torres. }\end{array}$ & $\begin{array}{l}\text { Comércio varejista; serviços } \\
\text { gerais e especializados; } \\
\text { Centros de distribuição } \\
\text { atacadista e mineração de areia } \\
\text { (em Osório); } \\
\text { Parques eólicos (Osório, } \\
\text { Tramandaí e Xangri-Lá); } \\
\text { Indústrias da construção civil, } \\
\text { madeira, do mobiliário e de } \\
\text { confecções; } \\
\text { Turismo esportivo e de eventos; } \\
\text { Lazer e recreação, } \\
\text { principalmente para a terceira } \\
\text { idade. }\end{array}$ \\
\hline
\end{tabular}

Fonte: Adaptado de Strohaecker (2007, p.180).

No quadro apresentado, é possível verificar que, nos municípios do litoral, existe uma semelhança na base econômica e vocação para o desenvolvimento. Como caracterizou Strohaecker (2007), os municípios em destaque apresentam-se como sendo de segunda residência. 
Em outra análise sobre o litoral, foi realizado, pelo COREDE (2017, p. 74), entre os meses de maio e julho de 2016, um estudo que dividiu o litoral segundo sua localização e característica sem três grupos:

I. Municípios mais rurais, com forte potencialidade ambiental: são aqueles municípios mais ao norte e noroeste do COREDE Litoral, localizadas a oeste da BR101 e que têm como características menores índices de urbanização e, de forma geral, também com menor população. Nesse grupo estão os municípios de Caraá, Dom Pedro de Alcântara, Itati, Mampituba, Maquiné, Morrinhos do Sul, Terra de Areia, Três Cachoeiras e Três Forquilhas.

II. Municípios costeiros, com grande potencial de veraneio: são aqueles municípios que possuem praias e balneários, localizados a leste da BR101, muito urbanizados, com populações acima da média do COREDE e que, nos meses do verão, chegam a quadruplicar o número de habitantes. Esse grupo também é o que apresenta uma economia mais dinâmica. Nesse grupo estão os municípios de Arroio do Sal, Balneário Pinhal, Capão da Canoa, Cidreira, Imbé, Osório, Torres, Tramandaí e Xangri-Lá.

III. Municípios ao sul do COREDE: esses três municípios distinguem-se por possuírem grande relação com a Lagoa dos Patos e por estarem localizado ao Sul da RS40, importante via de ligação com Porto Alegre. Embora bem urbanos, sua urbanização é menor do que os municípios costeiros. Nesse grupo estão três municípios, Capivari do Sul, Palmares do Sul e Mostardas.

Alguns fatores podem dinamizar e potencializar o desenvolvimento do litoral, conforme Strohaecker (2007), destacando a importância de investimentos públicos e privados de pequeno, médio e grande porte. A região apresenta uma estrutura de estradas federais e estaduais de boa acessibilidade. Elementos naturais compõem a paisagem que qualifica a região, por exemplo o mar e a lagoa e todos seus recursos naturais. Há também investimentos em praças, parques urbanos e estrutura comercial como shopping e hipermercados. Assim, é de grande importância disponibilizar serviços de qualidade de saúde e de educação.

O turismo e a população de veraneio que dinamizam a região do litoral carecem de uma maior infraestrutura para se localizar, hospedar e se alimentar em todos os meses do ano (COREDE, 2017). Para Barretto (1995, p. 39), os equipamentos do meio urbano podem ser compreendidos na seguinte equação: “[...] infraestrutura de acesso + infraestrutura básica urbana + equipamentos turísticos + equipamentos de apoio = infraestrutura turística”.

Paiva (2004, p. 131) descreve que o ponto de partida para ações públicas para o desenvolvimento regional "[...] é um diagnóstico das potencialidades e dos estrangulamentos" nos diversos setores e territórios. Portanto, é necessário compreender a dinâmica do mercado, identificando suas fragilidades.

Pensando estrategicamente na gestão do litoral, o planejamento elaborado pelo COREDE (2017), para o período de 2015/2030, apresenta os seguintes pontos de partida: 
VISÃO: "Ser uma região de respeito à diversidade cultural e ambiental, de produção sustentável e com qualidade de vida”. (COREDE, 2017, p. 100)

VOCAÇÃO:

Forte produção primária, com processamento e produção sustentável com base ecológica na fruticultura tropical e nativa, na olericultura e na pesca artesanal. Destaque para agropecuária e orizicultura. Um setor de serviços ligados ao turismo pujante e diversificado, com serviços de porte na educação superior e na saúde. Destaque para a produção de energia sustentável. (COREDE, 2017, p. 100)

VALORES: "Respeito às riquezas naturais e à diversidade sociocultural e ao prazer de bem receber". (COREDE, 2017, p. 100)

Para o desenvolvimento dessa região, é preciso respeitar as características naturais, a diversidade sociocultural e ambiental desses municípios, ou seja, os mais rurais, com forte potencialidade de exploração de atividades voltadas à agricultura familiar, ao agronegócio e também ao turismo ecológico. Os municípios costeiros têm grande potencial para atividades voltadas para o turismo de veraneio e afins.

\subsection{DESAFIOS E LIMITAÇÕES PARA O DESENVOLVIMENTO DO LITORAL} NORTE

Quanto aos desafios e limitações para o desenvolvimento do litoral, mais precisamente no município de Capão da Canoa, destaca-se, neste estudo, a adequação das estratégias do planejamento e gestão do território no atendimento das demandas por serviços públicos. Destacam-se, também, no setor privado, empresas com especialização na oferta de produtos e serviços na área do turismo.

Alguns fatores envolvem o planejamento do turismo. Barretto (1995) indica o acesso das vias públicas, saneamento básico, alojamento, alimentação e atividades de recreação. Segundo o teórico, “[...] é preciso criar uma série de comodidades que permitam que as pessoas saiam de casa sem risco de vida e com algum conforto”. (1995, p. 14).

Com o objetivo de sistematizar a apresentação dos desafios e limitações, evidencia-se, a seguir, no Quadro 2, a matriz FOFA ${ }^{1}$, com base nas matrizes e dimensões apresentadas pelo COREDE que mostra as potencialidades, desafios, riscos e limitações para o desenvolvimento da região.

\footnotetext{
${ }^{1}$ A matriz FOFA é um instrumento de análise de negócio simples e valioso. Sua finalidade é detectar pontos fortes e fracos de uma empresa, com o objetivo de torná-la mais eficiente e competitiva, corrigindo assim suas deficiências. O nome é um acrônimo para Forças, Oportunidades, Fraquezas e Ameaças, a matriz deriva da análise SWOT (Strenghts, Weaknesses, Opportunities e Threats). (SEBRAE, 2016).
} 
Quadro 2 - Matriz FOFA

\begin{tabular}{|l|l|}
\hline FORÇAS & \multicolumn{1}{|c|}{ OPORTUNIDADES } \\
\hline Malha Rodoviária & Turismo \\
Potencial Eólico & Ecoturismo \\
Potencial Hídrico & Fluxo de veranistas no final de semana \\
Hospitais Regionais e a proximidade de POA & Atração de idosos \\
Rede hoteleira & \\
\hline FRAQUEZAS & AMEAÇAS \\
\hline Uso na faixa de lagoas e praia & Turismo de massa e os conflitos ambientais \\
Separação e destinação de resíduos & Mercado sazonal \\
Tratamento de esgoto & Déficit policiais e viaturas \\
Urbanização desordenada & Permanência de famílias na baixa temporada \\
Capacitação do pequeno empreendedor & Drogadição \\
Estrutura e Gestão do Turismo & Falta de envolvimento político \\
Calendário de eventos & \\
Qualidade de atendimento ao turista & \\
\hline
\end{tabular}

Fonte: Adaptado de COREDE, 2017.

Na região do litoral norte, especificamente em Capão da Canoa, território deste estudo, é possível verificar algumas forças que podem ser divididas em estrutural: Potencial Eólico e Hídrico, Malha Rodoviária que conta com a BR 101 e Estrado do Mar. A presença de hospitais e a proximidade geográfica com Porto Alegre compõem um aspecto social. Na dimensão econômica, é possível encontrar inúmeros hotéis e pousadas, embora de pequeno porte, por toda extensão da praia. Com relação às oportunidades, pode-se destacar, na dimensão econômica, o turismo de veraneio e o ecoturismo, geração de energia sustentável com a instalação de parques eólicos (o que é uma realidade em muitos municípios).

Nas fraquezas, em relação ao planejamento e gestão do território apontadas na dimensão estrutural, destacam-se os conflitos urbanos no uso e na ocupação do solo na faixa de lagoa e praia, separação e destinação dos resíduos sólidos, tratamento de esgoto e urbanização desordenada. Na dimensão econômica, a estrutura e a gestão do turismo são apontadas como fracas. Uma fraqueza destacada é a falta de integração entre os municípios no desenvolvimento de uma programação de eventos para promover o turismo na baixa temporada de veraneio. Na dimensão social, foi indicada a precariedade de inserção das comunidades tradicionais. Nesse sentido, cabem novos estudos sobre tais comunidades e sua relação com a sociedade.

Por fim, o estudo do COREDE também aponta algumas ameaças ao desenvolvimento da região, como o próprio turismo e seus impactos ao meio ambiente e a baixa temporada impactando na economia dos municípios. No aspecto social, o baixo efetivo policial, os altos 
índices de drogadição e a permanência de famílias no período de baixa temporada provocam grandes desafios à gestão pública municipal quanto à segurança e à saúde pública.

"Um turismo que aconteça sem o cuidado com tais questões tende a gerar desequilíbrios e impactos, tornando-se insustentável social e culturalmente" (ARAÚJO et al., 2017, p. 9). É importante ressaltar que o turismo de massa envolve aspectos positivos na dimensão econômica, mas, em relação ao social e ambiental, é preciso considerar os seus impactos nesses espaços ditos turísticos.

As consequências do grande fluxo de pessoas nesses ambientes, extremamente sensíveis, fazem com que o planejamento dos espaços, dos equipamentos e das atividades turísticas se apresente como fundamental para evitar os danos sobre os meios visitados e manter a atratividade dos recursos para as futuras gerações (RUSCHAMANN, 1997, p. 9).

A identificação dos desafios e limitações para o desenvolvimento do turismo no litoral que tem como patrimônio seu ambiente natural, composto pela costa oceânica e recursos hídricos formados pela imensa bacia hidrográfica, é fundamental para a preservação do local. Sabe-se que os recursos naturais, que devem ser preservados, são responsáveis pela atração de grande parte dos veranistas e turistas para a região. Isso porque o desenvolvimento da matriz econômica e a produção rural são dependentes desses recursos.

“Os recursos turísticos naturais são aqueles nos quais não houve intervenção do homem, tais como florestas, acidentes geográficos e formações rochosas. Atualmente é difícil encontrar recursos naturais em estado puro [...]" (BARRETO, 1995, p. 40). Dessa forma, o estudioso destaca a importância dos instrumentos de planejamento e gestão dos recursos naturais em equilíbrio ao desenvolvimento. Nesse sentido, a efetivação da legislação ambiental do litoral norte é um desafio para o planejamento e a gestão sustentável do território. A partir disso,

[...] ]observa-se uma preocupação para que a região conserve e recupere a vegetação das encostas de morros e das matas ciliares para proteger o solo da erosão e a rede de drenagem superficial. Também é reconhecida a necessidade de preservação e recuperação dos resquícios de Mata Atlântica e de ambientes de dunas, banhados e restingas da Região por meio da criação ou manutenção de áreas de pesquisa, de parques e reservas naturais e de áreas indígenas (COREDE, 2017, p. 30).

Ainda sobre a efetivação da legislação ambiental, o diagnóstico apresentado pelo COREDE (2017, p.32) destacou duas questões que precisam atenção especial, com a questão ambiental:

i) Baixos indicadores de saneamento básico: o lançamento de esgotos domésticos sem tratamento nos corpos hídricos da Região e no mar contribui para a 
degradação dos mananciais e acaba por contaminar as praias, locais de contato direto da população;

ii) Fragilidades ambientais: a especulação imobiliária e a ocupação desordenada do solo urbano contribuem para a degradação dos ambientes costeiros e dos recursos hídricos. É importante para a Região a promoção da recuperação da vegetação das encostas de morros, das matas ciliares, para proteger o solo da erosão, e da rede de drenagem superficial.

Cabe destacar também a importância da participação da população dos lugares turísticos de forma colaborativa, para que se tenha um maior aproveitamento respeitando o “[...] patrimônio natural e cultural incentivando a conservação e a busca da formação de uma consciência socioambiental” (FERNADES; PEREIRA, 2017, p. 542). Nesse sentido, pode-se destacar a importância do exercício da cidadania formal ou não, mas que está diretamente ligado ao empoderamento social (SIEDENBERG, 2010).

No aspecto da legislação, Strohaecker (2007) reconhece como fatores estabilizadores do desenvolvimento a Legislação Ambiental; Legislação referente ao Patrimônio da União; Legislação Urbanística Federal, Estadual e Municipal com os Planos Diretores.

De acordo com Ansarah (2001, p. 22), “O turismo sustentável tem estado presente em todas as novas orientações turísticas". E o litoral conta com importantes unidades de conservação, portanto é preciso ter não somente uma legislação ambiental eficiente nesse território, mas também um envolvimento da população, pois é uma região com grande potencial de desenvolvimento de atividades turísticas que, quando bem geridas, promovem a preservação ambiental e a sustentabilidade dessas atividades.

Sobre o envolvimento da população local, os autores Fernandes e Pereira (2017, p. 542) apontam que algumas pessoas dos lugares ditos turísticos “[...] não se comportam de forma colaborativa e respeitosa, na própria origem, para que exista maior índice de utilização sustentável do patrimônio natural e cultural incentivando a conservação e a busca da formação de uma consciência socioambiental".

Strohaecker (2007, p. 182) reconhece como fatores inibidores do desenvolvimento a "[...] carência de infraestrutura, poluição hídrica, sonora e visual, violência urbana, desemprego, assentamentos espontâneos e pobreza". Na demanda por mais serviços públicos, destacam-se as no setor da saúde, segurança pública e habitação, pois essas já se demonstram deficientes no recorte territorial de pesquisa. Sabe-se que outras demandas são essenciais, como educação e estrutura urbana de qualidade, principalmente em relação à acessibilidade em espaços públicos.

O COREDE Litoral (2017) apresentou em seu diagnóstico que a região obteve um crescimento na faixa etária acima de 65 anos maior que a média estadual. Portanto, deve o 
planejamento do território para o turismo de terceira idade oferecer produtos e serviços específicos a esse público. Então, é preciso atentar "[...] que terão uma enorme diferença quanto a limitações físicas" (BARRETTO, 1995, p. 23). Sabe-se que uma população mais envelhecida implica inúmeros desafios à sociedade e ao poder público, principalmente nas questões relativas aserviços de saúde e à previdência, assim como uma estrutura urbana com acessibilidade adequada ao perfil do turista e novo morador.

Um dos aspectos com bastante fragilidade no litoral é a segurança pública nessa região, porque a falta de segurança e os altos índices de criminalidade estão sempre no centro dos debates da gestão pública. "A taxa de roubos e furtos é a soma dos dados de roubos de carro e furtos de carro para cada mil habitantes da localidade" (COREDE, 2017, p.51). Com base no ano de 2014, nas taxas de roubos e furtos, observa-se que, para o Rio Grande do Sul, foi de 23,5, e no litoral foi de 34,3, bem superior ao Estado nesse período analisado.

O crescimento demográfico nesses municípios agrava a questão do déficit habitacional. Ele é resultado do crescimento populacional da região, marcado pelo intenso fluxo migratório, um deslocamento intenso de várias regiões do estado para as principais cidades litorâneas.

A falta de moradiasresulta no déficit habitacional que abrange famílias de diversas faixas de renda, mas, principalmente, a população de classes mais baixas. A exemplo de Capão da $\mathrm{Canoa}^{2}$, é possível identificar um quadro de necessidades habitacionais ou situações que configuram a inadequação de moradia, ou seja, as moradias apresentam alguma insuficiência ou até inexistência de infraestrutura urbana, como abastecimento de água, luz e coleta de lixo, entre outras (COREDE, 2017).

“Os padrões do urbanismo modernista foram aplicados a uma parte das cidades, formando verdadeiras 'ilhas de primeiro mundo' cercadas de ocupação ilegal promovidas por favelas, cortiços e loteamentos clandestinos” (MARICATO, 2008, p. 53, grifo do autor). A produção habitacional é uma das principais atividades econômicas da região, sendo protagonista na geração de emprego dos municípios. Essa dinâmica colabora para a supervalorização de terras, o que aumenta a disputa pelos territórios de melhor localização, promovendo a segregação socioespacial urbana com a periferização da população local.

\footnotetext{
${ }^{2}$ As taxas de migrações para o litoral na última década são bem expressivas. Na região, identificam-se dois grandes processos migratórios. O primeiro caracterizado por famílias de maior renda que vêm ao litoral em busca de um conforto e lazer após sua aposentadoria. Outro grupo, muitas vezes em situações de vulnerabilidade bem grande, é composto por aquelas famílias que anualmente no início do período de veraneio vêm ao litoral em busca de oportunidades de emprego e que acabam se fixando nos municípios muitas vezes de forma irregular. Capão da Canoa apresenta o maior déficit proporcional (11,5\%), seguido de Tramandaí, Imbé e Xangri-Lá que apresentam um déficit na ordem de 10\% dos domicílios (COREDE, 2017, p. 98).
} 
$\mathrm{O}$ " $[. .$.$] insuficiente planejamento urbano e a falta de oferta e programas que ampliem$ o acesso à habitação de interesse social acabam por induzir à ocupação de áreas inadequadas e APPs e a consolidação de assentamentos precários". (COREDE, 2017, p.53). Se por um lado o aumento populacional pode significar avanços, por outro a demanda por novas unidades habitacionais desafia a gestão dos territórios, principalmente na demanda por serviços públicos e políticas sociais.

“O turismo poderá continuar a crescer, mas isso não acontecerá apenas por obra de uma inércia natural” (BARRETTO, 1995, p. 96). A pouca especialização de empresas na oferta de produtos e serviços voltados para o turismo pode ser apontado como limitador do desenvolvimento.

[...] a necessidade de maiores investimentos para "bem receber" e um maior cuidado na qualificação daquela que talvez seja a "joia" do litoral, que é sua orla. [...]. Diversificar e integrar os distintos tipos de turismos existentes e potenciais da região; promover melhorias das infraestruturas de turismo e a qualificação técnica do setor. [...] Integração das diferentes gestões do turismo municipais, complementação com estudos e planejamento temático e qualificação da infraestrutura e mão de obra (COREDE, 2017, p. 93, grifos do autor).

Esse fato também pode ser verificado em estudo realizado por Borges (2016) que aponta o perfil das empresas que acompanharam o desenvolvimento do município é composto por uma estrutura enxuta, com um número mínimo de funcionários possível. O porte das empresas é concentrado em Microempresa (ME) composto por empresas locais (BORGES, 2016). Na região pesquisada, as atividades estão concentradas em Comércio e Serviços, e o público-alvo dessas empresas é o misto, ou seja, é composto por moradores do município e região pela proximidade geográfica com outros municípios e veranistas. Já o foco no turista/veranista é restrito, principalmente no período de alta temporada de verão, compreendido pelos meses de dezembro, janeiro e fevereiro.

O turismo (veraneio) tem uma forte ligação com o setor da construção civil no litoral: “[...] embora passe nesse momento por uma desaceleração, é responsável por uma grande cadeia que emprega muito dos trabalhadores da região" (COREDE, 2017, p. 77). É importante ressaltar que, principalmente, as empresas de serviços e as do segmento de construção civil têm o turista/veranista como público-alvo, principalmente pelo produto imobiliário de alto valor agregado, destinado às classes A e B. Poucas empresas da construção civil no município oferecem produtos para classes mais baixas, sendo uma justificativa a supervalorização dos imóveis nos últimos anos. 
O potencial para o comércio despertou, nos últimos anos, o interesse em grandes empresas de instalarem no município suas filiais, gerando um número maior de empregos como fator positivo. Porém, isso também serve de alerta aos empresários locais quando se verifica um baixo investimento em melhorias internas na empresa, pois a concorrência no mercado, agora globalizado, apresenta empresas de nível internacional e nacional com muita expertise de negócio.

Entre as atividades reflexas da atividade Turismo, destaca-se"[...] o setor de hotéis e pousadas que tem grande destaque na região. Cabe lembrar que muito se apontou da necessidade de melhorar a qualidade no atendimento ao turista [...]" (COREDE, 2017, p.76). Estudos do COREDE apontam o desafio de melhorar o atendimento ao turista que frequenta o litoral não somente na temporada de veraneio, mas também no restante do ano. "O turismo de boa qualidade poderá desenvolver-se na medida em que tiver bons recursos humanos, e isso só será possível quando todos os cidadãos tiverem educação e saúde garantidas" (BARRETTO, 1995, p. 97). Mesmo sendo uma região que depende de turismo, como base da economia, no segmento de turismo foi verificada uma grande deficiência em mão de obra qualificada (BORGES, 2016).

"No caso específico do turismo no Brasil, as formações são imprescindíveis, especialmente porque a matéria-prima são os serviços, que dependem fundamentalmente de qualificação da mão de obra" (ANSARAH, 2001, p. 14). É importante salientar que Capão da Canoa tem, nessa atividade, poucas pessoas empregadas. Pode-se concluir, assim, que essa não seja uma atividade muito explorada, embora a região do litoral apresente esse potencial, como já foi abordado em diversos estudos sobre o turismo no litoral norte (BORGES, 2016).

Em termos de Políticas Públicas ou programas de qualificação profissional, realizadas por parte da Administração Municipal (PMCC), o estudo, realizado por Borges (2016), apontou poucas ações do Poder Público Municipal voltadas ao aperfeiçoamento profissional da população local ligado à vocação da região. As ações realizadas podem ser consideradas positivas, no entanto não suficientes. As políticas de planejamento territorial e construção de um plano de turismo para a região do litoral norte é fundamental. Conforme destaca Ansarah (2001, p. 137), é “A administração dos pontos fracos e fortes com a implantação das diretrizes e projetos integrados envolvendo poder público, a iniciativa privada e, especialmente, a comunidade". O plano precisa contemplar todas as frentes de trabalho segundo mencionaram os autores Fernandes e Pereira (2017), seguindo os princípios da administração de forma planejada, organizada, com direção, comandada, coordenada e, por fim, controlada, principalmente, no sentindo de avaliar os resultados. 
Há um impasse quando o consentimento do fenômeno do turismo no que se refere ao planejamento do mesmo e às ações de ordenamento territorial de lugares ditos turísticos, pois nestes há apropriada inquietação quando não se percebe harmonização das técnicas, indicadas de uso do turismo sustentável durante confrontações com as efetivas ações dos gestores nos espaços utilizados pelo turismo (FERNANDES; PEREIRA, 2017, p. 542).

No mesmo sentido, Barretto (1995, p. 97) declara que "[...] há ainda um longo caminho a percorrer para que o turismo realize os benefícios sociais para os quais tem potencial". E, com um olhar mais amplo, destaca que é preciso promover melhorias significativas na qualidade de vida que favoreçam a justiça social, criando maiores possibilidades de promover o desenvolvimento no litoral norte do Rio Grande do Sul.

O litoral apresenta uma disparidade na gestão entre os municípios que colaboram com dois problemas de gestão. Um deles é a “[...] falta de associativismo entre produtores e comerciários dos diversos setores. O primeiro problema evidencia-se principalmente no turismo - mas não se restringe a apenas ele”. (COREDE, 2017, p. 78). Ainda no setor do turismo, é possível identificar "[...] falta de uma integração mais regional na gestão pública" (COREDE, 2017, p. 78). Conforme Dotto et al. (2017), a parceria entre o público e o privado poderia ser solução para minimizar os efeitos da crise no Estado. Na região do litoral norte, não há uma gestão intermunicipal voltada para a gestão do turismo.

O processo de planejamento municipal para o desenvolvimento do turismo é uma tarefa coletiva. "Planejar o turismo é um diálogo constante e um processo de negociação entre os atores sociais interessados, assegurando que ações, planos, programas e projetos expressem o consenso da sociedade local” (FERNANDES; PEREIRA, 2017, p. 547).

Com a diversidade de atrativos turísticos no litoral, a estruturação de roteiros poderia ser uma possibilidade de estimular a sustentabilidade da atividade turística (DOTTO et al., 2017). Percebeu-se, por meio deste estudo, que as ações são tímidas e acontecem de maneira fragmentada e desarticulada em cada município com planejamento de curto prazo, talvez somente no período da gestão do atual governo.

Conforme os autores, é importante destacar que o planejamento e a gestão do território dependem da integração dos agentes para o desenvolvimento local. Tomazzoni e Costa (2015) complementam que é preciso criar uma articulação estratégica com ações de cooperação entre os agentes do desenvolvimento. Deve-se, então, criar um planejamento que contemple todas as áreas do desenvolvimento com ações focadas no mesmo objetivo, fomentando a troca de conhecimento e a experiência de cada agente, os órgãos públicos, as instituições de ensino e, sem menos importância, as empresas privadas. Quando houver união e a convergência dos 
interesses de todos os agentes envolvidos, acontecerá, de fato, o desenvolvimento regional. Porém, para isso, é preciso criar um planejamento e desenvolver instrumentos para a gestão do território, visando ao desenvolvimento socioeconômico.

\section{CONSIDERAÇÕES FINAIS}

Neste estudo, que buscou apresentar as potencialidades para o desenvolvimento do turismo em Capão da Canoa, na região do litoral norte do Rio Grande do Sul, verificou-se que, para potencializar a atratividade do turismo no litoral, é no mínimo interessante desenvolver um plano integrado para o turismo na região. Conforme foi destacado por Tomazzoni e Costa (2015), é fundamental promover uma maior cooperação entre os órgãos públicos e organizações privadas dos municípios desse recorte territorial. A integração turística no litoral resultaria em um aumento no fluxo de turistas durante o restante do ano, com a redução dos impactos da sazonalidade e o aumento do efeito multiplicador do turismo.

É preciso desenvolver o perfil empreendedor no segmento turismo e lazer, com foco no desenvolvimento do município, pensando de maneira estratégica na oferta do produto turístico com bens e serviços essenciais para satisfazer aos visitantes. Dessa forma, é possível ampliar o efeito multiplicador apresentado por Barreto (1995). Para explorar as potencialidades, é preciso encontrar um equilíbrio entre o desenvolvimento econômico e social, controlando os impactos negativos na subutilização, bem como a degradação de espaço urbano e a preservação dos recursos naturais, garantindo a qualidade de vida e a promoção da justiça social no âmbito local e regional.

Também com o objetivo de identificar os desafios e as limitações para a gestão do território urbano na exploração do potencial turístico, ressalta-se que o turismo fomenta indiretamente diversas atividades de consumo e tem fundamental importância para a economia, uma vez que foi um dos motivos que marcou a ocupação do litoral norte. E os fatores que indicam oportunidades para o desenvolvimento econômico do litoral estão diretamente ligados ao turismo que, atualmente, apresenta uma base econômica fraca, com pouca diversidade de produtos e serviços. Além da falta de planejamento municipal em saneamento básico, moradia, transporte e mobilidade urbana, esses fatores podem significar uma limitação do desenvolvimento regional.

Por fim, este estudo comprova que existe um potencial para o desenvolvimento regional por meio do turismo em diversos segmentos, com capacidade para atrair novos turistas. Porém, esse desenvolvimento tropeça em desafios e limitações. A partir dessa 
Revista Tecnologia e Ambiente, v. 25, 2019, Criciúma, Santa Catarina/SC ISSN Eletrônico 2358-9426 e ISSN Impresso 1413-8131

temática, sugerem-se novos estudos voltados para a construção de um roteiro turístico integrado, envolvendo o turismo de praia, o rural e o ecológico.

\section{REFERÊNCIAS}

ANSARAH, Marília Gomes dos Reis. Turismo: segmentação de mercado. 4.ed. São Paulo: Futura, 2001.

ARAÚJO, Wilson Alves et al. Desenvolvimento local, turismo e populações tradicionais: elementos conceituais e apontamentos para reflexão, 2017. Disponível em: <http://www.scielo.br/pdf/inter/v18n4/1518-7012-inter-18-04-0005.pdf>. Acesso em: 7 ago. 2018.

BARRETTO, Margarita. Manual de iniciação ao estudo do turismo. 12. ed. Campinas: Papirus, 1995.

BORGES, Juarez Camargo. O mercado de trabalho e a qualificação do trabalhador no município de Capão da Canoa: a visão dos empregadores. 2016. 138f. Dissertação (Mestrado em Desenvolvimento Regional) - Faculdades Integradas de Taquara-RS, 2016.

BRASIL. Ministério do Turismo. Plano Nacional de Turismo 2018-2022. Disponível em: <http://www.turismo.gov.br/2015-03-09-13-54-27.html>. Acesso em: 10 maio 2018.

COREDE LITORAL (Osório). Planejamento Estratégico COREDE Litoral.Osório: S/e, 2017. Disponível em: <http://planejamento.rs.gov.br/upload/arquivos/201710/09144219plano-litoral.pdf $>$. Acesso em: 25 maio 2018.

DOTTO, Dalva Maria Righiet al. Gestão Municipal e Ações Integradas Para o Fortalecimento do Turismo no Território Quarta Colônia, RS, Brasil (2017). Revista Turismo - Visão e Ação - Eletrônica, v. 10, n. 1, p. 132-157, 2018.Disponível em: <https://siaiap32.univali.br/seer/index.php/rtva/article/view/12160. Acesso em: 8 ago. 2018.

FERNANDES, Marcel Waline de Carvalho Ferraz. PEREIRA, Yára Christina Cesário. Turismo e Educação: turismo nos anos iniciais do ensino fundamental em escolas do município de Fortaleza no Estado do Ceará. Revista Turismo - Visão e Ação - Eletrônica, v. 19, n. 3, p. 540-565, 2017. Disponível em: $<$ https://siaiap32.univali.br/seer/index.php/rtva/article/view/11668/6712〉. Acesso em: 1 maio 2018.

MARICATO, Ermínia. Globalização e política urbana na periferia do capitalismo. In: RIBEIRO, L.C.Q.; SANTOS JUNIOR, O.A. (Orgs.). As Metrópoles e a Questão Social Brasileira.Rio de Janeiro:Revan; Fase. p. 51-76, 2008.v. 1.

MOSER, Giancarlo; MULLER, Salvio Alexandre (Orgs.) Sociologia aplicada ao turismo Subsídios para estudos. Indaial: Asselvi, 2002.

PAIVA, Carlos Águedo. Como identificar e mobilizar o potencial de desenvolvimento de uma região? Porto Alegre: Fee, 2004.

RUSCHMANN, Doris Van De Meene. Turismo e planejamento sustentável: a proteção do meio ambiente. 4. ed. Campinas: Papirus, 1997.

SANCHO, Amparo. Introdução ao turismo. São Paulo: Rocca, 2001.

SEBRAE. Use a matriz FOFA para corrigir deficiências e melhorar a empresa,

2016. Disponível em: <http://www.sebrae.com.br/sites/PortalSebrae/artigos/use-a-matrizfofa-para-corrigir-deficiencias-e-melhorar-aempresa,9cd2798be83ea410VgnVCM2000003c74010aRCRD>. Acesso em: 18 ago. 2018. SEN, Amartya. Desenvolvimento como liberdade. São Paulo: Companhia das Letras, 2000. STROHAECKER, Tânia Marques. A urbanização no litoral norte do estado do Rio Grande do Sul: contribuição para a gestão urbana ambiental do município de Capão da Canoa. 2007. 398 f. Dissertação de Mestrado, Programa de Pós-graduação em Geociências, 
Instituto de Geociências, Universidade Federal do Rio Grande do Sul - UFRGS, Porto Alegre, 2007.

SIEDENBERG, Dieter. Fundamentos e técnicas de planejamento estratégico local/regional. Santa Cruz do Sul. EDUNISC, 2010.

TOMAZZONI, Edegar Luis. Turismo e desenvolvimento regional: dimensões, elementos e indicadores. Caxias do Sul. Educs, 2009.

TOMAZZONI, Edegar Luis; COSTA, Juliana Soares. Ações estratégicas e visões dos atores do cluster de turismo da cidade de São Paulo. Revista Brasileira de Pesquisa em Turismo, v. $9, \quad$ n. $1, \quad$ p. 3-21, 2015. Disponível em: $<$ http://www.spell.org.br/documentos/ver/35003/acoes-estrategicas-e-visoes-dos-atores-docluster-de-turismo-da-cidade-de-sao-paulo>. Acesso em 8: ago 2018. 